Meta

Journal des traducteurs

Translators' Journal

\title{
Vicisitudes de algunas equivalencias en el discurso de la diplomacia hispano-mapuche en el Chile colonial
}

\section{Danielle Zaslavsky, Gertrudis Payas et Iveth Carreño}

Volume 64, numéro 3, décembre 2019

URI : https://id.erudit.org/iderudit/1070533ar

DOI : https://doi.org/10.7202/1070533ar

Aller au sommaire du numéro

\section{Éditeur(s)}

Les Presses de l’Université de Montréal

\section{ISSN}

0026-0452 (imprimé)

1492-1421 (numérique)

Découvrir la revue

Citer cet article

Zaslavsky, D., Payas, G. \& Carreño, I. (2019). Vicisitudes de algunas equivalencias en el discurso de la diplomacia hispano-mapuche en el Chile colonial. Meta, 64(3), 648-667. https://doi.org/10.7202/1070533ar
Résumé de l'article

Les parlamentos hispano-mapuche furent des conférences de paix tenues au sud du Chili entre l'armée coloniale espagnole et les autorités mapuche. Ces traités ont engendré un vocabulaire politique particulier, produit de la relation entre les deux communautés. Le présent article aborde l'occurrence, dans les traités de paix, du vocable parlamento, dans ses deux acceptions principales présentes tout au long du XVII ${ }^{\mathrm{e}}$ - discours et réunion- pour devenir au cours du XVIII ${ }^{\mathrm{e}}$ un terme clé du vocabulaire politique des modalités d'interaction entre la couronne espagnole et les Mapuches. L'étude du trajet thématique et discursif de ce vocable et de ses usages, ainsi que de celui d'autres vocables désignant les acteurs et l'espace physique de la cérémonie, repose sur une réflexion traductologique, à l'aune d'une approche sociohistorique et discursive, tout en recourant à certains outils et concepts de la terminologie. Le présent travail, sur un cas précis d'équivalence de traduction, prétend contribuer à l'histoire de la traduction, à l'histoire générale et à celle des concepts politiques. 


\title{
Vicisitudes de algunas equivalencias en el discurso de la diplomacia hispano-mapuche en el Chile colonial ${ }^{1}$
}

\author{
DANIELLE ZASLAVSKY \\ El Colegio de México, Ciudad de México, México \\ dzasla@colmex.mx
}

GERTRUDIS PAYAS

Universidad Católica de Temuco, Temuco, Chile gpayas@uct.cl

\author{
IVETH CARREÑO \\ Universidad Católica de Temuco, Temuco, Chile \\ scarreno@uct.cl
}

\section{RÉSUMÉ}

Les parlamentos hispano-mapuche furent des conférences de paix tenues au sud du Chili entre l'armée coloniale espagnole et les autorités mapuche. Ces traités ont engendré un vocabulaire politique particulier, produit de la relation entre les deux communautés. Le présent article aborde l'occurrence, dans les traités de paix, du vocable parlamento, dans

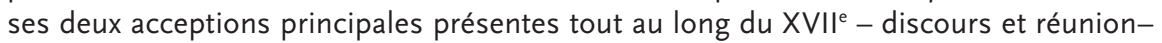
pour devenir au cours du XVIII e un terme clé du vocabulaire politique des modalités d'interaction entre la couronne espagnole et les Mapuches. L'étude du trajet thématique et discursif de ce vocable et de ses usages, ainsi que de celui d'autres vocables désignant les acteurs et l'espace physique de la cérémonie, repose sur une réflexion traductologique, à l'aune d'une approche sociohistorique et discursive, tout en recourant à certains outils et concepts de la terminologie. Le présent travail, sur un cas précis d'équivalence de traduction, prétend contribuer à l'histoire de la traduction, à l'histoire générale et à celle des concepts politiques.

\begin{abstract}
The Mapuche - Spanish parlamentos were peace assemblies held during the colonial period between the Spanish army and the Mapuche authorities in southern Chile. The interaction between these two communities led to the creation a specific political vocabulary. This article examines the occurrence of the word parlamento by addressing the two main senses attributed to it - speech and assembly/gathering - in the peace treaties of the seventeenth century. Our argument is twofold. Firstly, we contend that, over the course of the eighteen century, the latter sense imposed over the former. Secondly, we argue that, during the same period, the word entered the political vocabulary of the interaction modalities between the Spanish Crown and the Chilean Mapuche. Drawing both on socio-historical and discursive approaches and on terminology concepts and tools, this article examines the thematic trajectory of the word parlamento and its network of meanings, as well as that of other words that referred to the actors and the physical settings where said assemblies took place. Hence, by analyzing a particular case of translation equivalence, it aims to contribute to the history of translation, general history, as well as to the history of political concepts.
\end{abstract}




\section{RESUMEN}

Los parlamentos hispano-mapuches fueron conferencias de paz entre el ejército colonial español y las autoridades mapuche en el sur de Chile, que dieron lugar a un vocabulario político específico, producto de la relación entre las dos comunidades. Se analiza aquí la ocurrencia de la palabra parlamento en los tratados de paz, en sus dos acepciones principales - discurso y reunión - presentes durante todo el siglo XVII, observando cómo, a lo largo del XVIII, la segunda acepción se va imponiendo y la palabra entra definitivamente en el vocabulario político de las modalidades de interacción entre la corona española y los mapuche. Este estudio del trayecto temático-discursivo de la palabra parlamento y su red de significados, así como de algunos otros vocablos que fueron designando a los actores y al espacio físico donde se realizaba el acto, descansa en una reflexión traductológica con un enfoque sociohistórico y discursivo, y recurre asimismo a instrumentos y conceptos de la terminología. El trabajo, que se centra en un caso particular de equivalencia de traducción, pretende aportar tanto a la historia de la traducción como a la historia general y la historia de los conceptos políticos.

\section{MOTS-CLÉS/ KEYWORDS/PALABRAS CLAVE}

médiation, diplomatie hispano-mapuche, histoire coloniale, trajet thématique, discours mediation, Mapuche-Spanish diplomacy, Colonial history, thematic trajectory, discourse mediación, diplomacia hispano-mapuche, historia colonial, trayecto temático, discurso

\section{Los parlamentos hispano-mapuches: contexto histórico y lingüístico}

\subsection{El contexto político}

En el imperio español de América, el territorio que abarcaba los valles al este de los Andes desde el gran desierto de Atacama hasta los confines del continente, conocido primero como Reino de Chile y después agregado al virreinato del Perú como Capitanía, se caracterizó por el esfuerzo militar que los españoles tuvieron que desplegar para su conquista. De hecho, los mapuche («mapu»= tierra, «che»= gente), la etnia principal, se habían enfrentado ya a la invasión inca, que en algunas zonas había logrado cooptar a las autoridades locales e instaurado sus instituciones. Los incas fueron, sin embargo, impedidos de seguir adelante al llegar al gran río Biobío, como lo fueron después los españoles, obligados éstos a permanecer en esa frontera, donde establecieron una línea de fuertes defendidos por un ejército permanente ${ }^{2}$. Los valientes mapuche, o araucanos, «hombres robustos, espaldas grandes, pechos levantados, recios miembros, de nervios bien fornidos; ágiles, desenvueltos, alentados, animosos, valientes, atrevidos, duros en el trabajo y sufridores de fríos mortales, hambres y calores», cantados por el soldado poeta Alonso de Ercilla (1569/1962: 27) siguieron resistiendo después de la campaña de los primeros conquistadores, Diego de Almagro y Pedro de Valdivia, y lograron lo que otras naciones autóctonas no pudieron: conservar un reconocimiento, relativo si se quiere, de autonomía política al sur del río Biobío durante todo el periodo colonial.

Lingüísticamente el territorio de Chile era bastante homogéneo, con una lengua «general» (denominación que se solía dar a la lengua de más curso), la lengua araucana, hoy mapudungun, con variantes dialectales, que se fue perdiendo en la mitad norte y los valles centrales a medida que avanzó la conquista y fueron desplazadas y dispersadas las poblaciones para sostener el esfuerzo bélico, la minería y otras actividades. Esas zonas centrales se mestizaron y adoptaron la lengua castellana con 
relativa rapidez. El mapudungun se mantuvo al sur del río Biobío, en el territorio autónomo mapuche, como lengua oral, solo escrita por los misioneros.

Después de décadas de enfrentamientos y hostigamientos mutuos, en un solemne encuentro efectuado en 1641 en los llanos de Quillín (a unos $600 \mathrm{~km}$ al sur de la actual Santiago) la corona española formalizó por medio del Tratado (o Paces) de Quillín, el reconocimiento de una frontera que se había ya perfilado con la construcción de una línea de fuertes a comienzos de siglo y se sella la claudicación y el abandono definitivo de la conquista. Al sur del río Biobío, entonces, gozaron los mapuche de una suerte de autonomía desde principios del XVII hasta la independencia. Durante este largo periodo sostuvieron autoridades de ambos bandos unas relaciones de cooperación con prácticas diplomáticas muy cercanas al Jus Gentium ${ }^{3}$. Efectivamente, las relaciones fronterizas se regularon sobre la base de solemnes tratados de paz, que en la historia y en la variante del español chileno se conocen hasta el día de hoy como parlamentos. Fueron auténticas conferencias cumbre, anticipadas con gran formalidad, convocadas regularmente, y a las que acudían autoridades españolas y mapuche, con acompañamiento y séquito, totalizando a veces miles de personas.

Hubo en total por lo menos 50 parlamentos entre 1593 y 1803, de los cuales dieciséis, entre los años de 1647 y 1803, corresponden a la modalidad más solemne de Parlamentos Generales (Zavala 2011, 2015; Dillehay y Zavala 2013).

\subsection{Intérpretes y mediadores en los parlamentos}

Como los mapuche no abandonaron su lengua ni cedieron (en términos generales) a los intentos de escolarización ${ }^{4}$ y adoctrinamiento, el esfuerzo diplomático se tuvo que apoyar en intérpretes e intermediarios bilingües formalizados. Por eso, el aparato institucional de mediadores del ejército es, efectivamente, una de las principales características de las relaciones políticas hispano-mapuches que se evidencia en los parlamentos (Payàs, Zavala et al. 2012; Zavala y Payàs 2015). Ya desde los primeros, las actas respectivas identifican al intérprete general o lengua ${ }^{5}$ general:

Para que mejor se entendiese esta seguridad que me daban llamé a los lenguas genera-

les, capitán Luis de Góngora y capitán Juan Bautista Pinto y la repetí en su presencia de ellos para que lo testificasen después. (Paces de Paicaví 1612; Payàs 2018: 95) ${ }^{6}$

Su presencia era obligada, como lo da a entender el jesuita Luis de Valdivia, gran conocedor de la lengua y representante de la autoridad ante los mapuche: «porque, aunque yo sé la lengua, fue voluntad del señor Virrey que hablase también por intérprete» (Paces de Paicaví 1612: 73). Expresiones como estas son comunes en todos los parlamentos, hasta los últimos del periodo colonial, y aunque podemos conjeturar que con el tiempo se produjo al menos un bilingüismo funcional en el territorio fronterizo, las autoridades españolas que venían de Santiago seguramente no sabían la lengua indígena. Por esta y por razones de un protocolo que quedó fijado para siempre, todos los parlamentos se celebraron en ambas lenguas mediante intérpretes y otros mediadores institucionalizados; de ahí que, si bien no poseemos testimonios directos, nos atrevemos a afirmar que, como principales agentes de la comunicación, los intérpretes, con sus respectivos mandantes, fueron los responsables de la consolidación de un lenguaje político bilingüe que aseguró la inteligibilidad mutua de los acuerdos. 
Disponemos hoy en día de una abundante literatura historiográfica sobre los parlamentos y su práctica; asimismo, contamos ya con algunos datos no sólo sobre los actores de la mediación, sino sobre las relaciones de poder implicadas por la mediación lingüística en los parlamentos (Malvestitti 2012); falta, sin embargo, aún un análisis detallado de sus aspectos discursivos, cuyo estudio, pese a las limitaciones debidas a la ausencia de textos en mapudungun, puede ser muy revelador de estas prácticas de mediación.

\section{Un enfoque discursivo y traductológico}

En un trabajo anterior (Payàs, Zavala et al. 2015) establecimos el momento en que Luis de Valdivia sugiere la equivalencia coyagtun/parlamento de Francia: «y esta junta llaman en su lengua coyagtun, que es como en Francia el parlamento» (Paces de Concepción 1605: 65), para designar la práctica de asamblea autóctona, intraétnica, y el momento (en 1617) en que parece haber cooptado la palabra para convocar a una reunión con los mapuche, es decir, una reunión interétnica. No obstante, ese estudio, basado fuertemente en las fuentes lexicográficas misionales, puede haber inducido a pensar que, una vez propuesta, la afortunada equivalencia de Luis de Valdivia fue adoptada sin vacilaciones y definitivamente por ambas partes. En cambio, al seguir el trayecto temático-discursivo de la noción-concepto (Guilhaumou 2000, 2005) de parlamento, así como de algunos otros vocablos desde su ocurrencia en los informes de los relatores desde fines del siglo XVI, pero sobre todo en las actas mismas de los parlamentos hasta el último parlamento colonial, de 1803, nos damos cuenta de que ésta tuvo una vida relativamente accidentada antes de designar sin ambigüedad esta práctica interétnica ${ }^{7}$.

Aunado a la herramienta terminológica, de gran utilidad para acotar el fenómeno léxico y medir las frecuencias de los vocablos analizados, el enfoque lingüísticodiscursivo que adoptamos aquí permite no sólo entender cómo se fue constituyendo el léxico político de las relaciones entre la corona española y los mapuche, léxico que, como decimos, muestra cierta inestabilidad, sino también, mediante el estudio de las interacciones de sus usuarios, captar lo que estaba en juego en las estrategias discursivas de unos y otros. Al rastrear el trayecto discursivo y temático de la voz parlamento en los informes que las autoridades españolas destinaban al rey, nos damos cuenta de que este vocablo, tomado del francés como traducción de una práctica autóctona y aclimatado en el español de Chile a raíz del encuentro interétnico, y que permanecerá con esta acepción única a lo largo de sus tres siglos de uso (Payàs, Zavala et al. 2015: 361), revela, a través de las coocurrencias y algunos desplazamientos léxicos en las interacciones de los distintos actores, sutiles estrategias de poder por parte de las autoridades españolas.

Redactadas en español, las actas de los parlamentos están constituidas por múltiples discursos referidos atribuidos a los participantes que tomaron la palabra, autoridades españoles y dignatarios mapuche, traducidos por el intérprete. Algunos de estos discursos se refieren como discursos directos, con sus debidas rupturas enunciativas, otros como indirectos, introducidos explícitamente por un verbo del decir. En ambos casos, y como siempre sucede con el discurso referido, el lector no tiene acceso al supuesto discurso fuente que le da origen y la paráfrasis se perfila como estrategia discursiva de traducción con una clara dimensión argumentativa (Zaslavsky 2012). 
La cuestión planteada aquí no es tanto reafirmar las relaciones que mantiene la traducción con el discurso referido, analogía consignada tempranamente por Jakobson (1959/1975), sino preguntarnos cómo podemos abordar estos discursos en toda su complejidad - referidos y traducidos - para que nos den acceso, por una parte, a cierta configuración léxica y por otra, a la construcción discursiva de sus enunciadores.

La palabra parlamento, cuya génesis describimos a continuación, no sólo estimuló la emergencia en los informes de algunos de sus derivados como parla o parlar, sino también la de varios otros vocablos que permitieron describir el escenario de las negociaciones, como la ramada, cobertizo de ramas que se erigía en cada parlamento y bajo el cual se realizan las negociaciones. Otros términos entrarán como préstamos naturalizados: será el caso de butalmapu (füta mapu, o tierra grande), para definir cada una de las cuatro alianzas político-territoriales mapuche, y sus aillareguas (aylla rewe, o nueve comunidades) conglomerado de rewe, que eran unidades territoriales menores, o de maloca (etimología dudosa), acción guerrera de los mapuche, que pronto adoptará la forma verbal maloquear. La polifonía que caracteriza estos discursos no sólo radica en esta heteroglosia producida por el encuentro de dos lenguas, sino también en la pluralidad de voces en las que las palabras toman cuerpo (Voloshinov 1929/2009) y en las heterogeneidades enunciativas constitutivas de todo discurso (Authier Revuz 1984).

\subsection{La muestra}

Del corpus de 52 documentos que constituyen la totalidad de los parlamentos identificados por José Manuel Zavala (Zavala 2015; Payàs 2018), hemos seleccionado una muestra de 22 documentos de archivo ${ }^{8}$, escalonados a lo largo de dos siglos; dieciséis corresponden a los parlamentos llamados «generales», es decir, los de mayor envergadura pues implicaban a los cuatro butalmapus (Zavala 2008), y los seis documentos restantes fueron seleccionados entre los primeros tratados de paz que firmó la corona española con el pueblo mapuche en función de la importancia política que tuvieron, como es el caso del Tratado de Quillín, de 1641, considerado por la corona española como parte de los tratados concertados con potencias extranjeras (Bengoa 2007, Zavala 2011).

Si bien cada documento de archivo corresponde a un parlamento, este puede contener varias piezas documentales que acompañan el acta o registro oficial del tratado: correspondencia personal o administrativa, actas de juntas de guerra, informes de diversa índole. Los parlamentos, por lo tanto, ofrecen piezas documentales que pertenecen a varios géneros discursivos, diversidad que nos permitirá aprehender su léxico en contextos discursivos más amplios.

\section{Parlamento: Génesis de una inteligibilidad mutua}

\subsection{Reconocimiento de una práctica ajena}

Varias son las fuentes españolas tempranas que atestiguan la costumbre mapuche de las «juntas a su usanza» (Góngora Marmolejo 1862, II: 124) para tratar asuntos de gobierno 9 . Los cronistas mencionan «los banquetes y borracheras» que caracterizan estas reuniones en las que «hacen sus acuerdos» (Vivar 1558/1966: 50) y el soldado 
poeta Alonso de Ercilla consignó en versos estas deliberaciones sobre cosas de guerra, describiendo de paso los lugares idílicos en que se hacían: «Hácese este concilio en un gracioso / asiento en mil florestas escogido / donde se muestra el campo más hermoso / de infinidad de flores guarnecido» (1569/1962: 25).

Reconocer que las poblaciones a las que intentaban conquistar tenían instituciones de deliberación que convenía conocer, negociar con el enemigo para hacer de él un aliado fue una práctica común en la conquista española. Los resultados de estas negociaciones fueron tratados de paz, por lo que en los primeros informes o actas llevan el nombre de paces $^{10}$.

\subsection{Primeras ocurrencias de la palabra «parlamento»}

En la documentación de estas primeras negociaciones la palabra parlamento no designa todavía la reunión interétnica, hispano-mapuche, sino que remite doblemente a las juntas de los mapuche y a sus discursos. La polisemia observada en las primeras ocurrencias de la palabra está muy cercana a la que existe en mapudungun, donde el acto y el verbo de deliberar (coyag), así como la instancia de deliberación (coyagtun), tienen la misma raíz.

En más de una ocasión, las actas mencionan que los caciques ${ }^{11}$ vuelven a la reunión, «después de haber entre sí tratado y hecho sus parlamentos» (Paces de Quilacoya 1593: 39), para formular sus condiciones a los españoles. El parlamento, en sus inicios, ya sea en un sentido u otro, en singular o en plural, es asunto de ellos, los mapuche: su/sus parlamentos.

$\mathrm{Al}$ establecer formalmente la equivalencia entre coyagtun y parlamento, para describir las juntas realizadas por los indios cuando tratan cosas de paz y de guerra, en una sección de la Memoria dirigida al rey que se encuentra anexa al informe de las paces suscritas en Concepción y otros lugares, en 1605, que lleva como título «Del modo que se gobiernan $»^{12}$, el jesuita Luis de Valdivia busca dar a las negociaciones hispano-mapuche la dimensión que tienen los tratados internacionales. Llama la atención, sin embargo, que la equivalencia se establece mediante el sentido que tiene la palabra en francés ${ }^{13}$ : "como es en Francia el parlamento», indicio de la temprana preeminencia de esta lengua en el ámbito político hispánico, considerando que la expansión del francés como lengua diplomática en los actos internacionales se dará más bien un siglo más tarde (Casanova 2008: 106), y de una carencia, real o imaginaria, de una noción equivalente en español, si bien la palabra parlamentar existe en castellano al menos desde el siglo XVI con el sentido de dirigirse al enemigo buscando la paz ${ }^{14}$, así como parlamento, derivada "probablemente del francés parlement» (Corominas 1987: 434). Se establece de esta manera la analogía de una otredad con otra otredad. La práctica propiamente autóctona, intraétnica, se mantendrá e incluso fortalecerá, articulándose a la negociación hispano-mapuche, interétnica, como consta en el siguiente ejemplo, donde se adopta, al parecer por primera vez la palabra parlamento para designar una reunión interétnica convocada por el bando español:

vinieron doce caciques de su provincia (...) los cuales afirmaron hicieron parlamento en Lleolleo toda la gente de Purén (...) mostráronse agradecidos los caciques que envié a llamar de todas las fronteras de Biobío para este parlamento. (Parlamento de Nacimiento 1617, op. cit: 104) 
Se conserva, paralelamente, el sentido de parlamento como discurso o perorata. En una carta anterior en la que relata a su superior eclesiástico las negociaciones de paz que ha emprendido en tierra enemiga, Luis de Valdivia llega a escribir: «Duró mi parlamento tres horas. La primera hablé yo por mí, las otras dos por el intérprete» (Parlamento de Catiray, 1612: 76). El juego de voces que intervienen en la narración de Valdivia sugiere aquí algo más. Al cambiar el posesivo de $3^{\text {a }}$ persona «sus parlamentos» por el deíctico de $1^{a}$ persona «mi parlamento», en vez de «mi razonamiento», palabra que solían usar las autoridades españolas y que Valdivia consigna en su diccionario de 1606 como equivalente de parlamento para traducir coyagtun (Payàs, Zavala et al. 2015: 364), el jesuita equipara sin ambages las modalidades de negociación de las dos comunidades, fenómeno poco frecuente en estos años. Efectivamente, vamos a ver en las páginas siguientes que esta incorporación lingüística de Valdivia, en la que puede percibirse una apertura hacia el mundo indígena, no significará un uso generalizado del término ${ }^{15}$.

\section{Un recorrido accidentado}

\subsection{La frecuencia}

Según el rastreo cronológico que pudimos hacer en los textos de nuestro corpus, repartidos en cuatro grandes periodos de los siglos XVII y XVIII, la palabra parlamento arroja 342 ocurrencias que se reparten de la siguiente manera.

CUADRO 1

Periodización y frecuencias

\begin{tabular}{|c|c|c|c|}
\hline Periodización & Fecha & Documento & Frec. \\
\hline \multirow{5}{*}{ Los inicios del modelo } & 1593 & Quilacoya* (5) & 5 \\
\hline & 1605 & Concepción * (9) & 1 \\
\hline & 1612 & Catiray & 3 \\
\hline & 1612 & Paicavi & 2 \\
\hline & 1617 & Nacimiento & 5 \\
\hline \multirow{6}{*}{$\begin{array}{l}\text { Segunda mitad del XVII: se confirma la } \\
\text { práctica y se afianza el léxico }\end{array}$} & 1641 & Quillin & 2 \\
\hline & 1647 & Quillin* (5) & 6 \\
\hline & 1692 & Yumbel & 15 \\
\hline & 1693 & Concepción* (2) & 22 \\
\hline & 1694 & Choque Choque & 21 \\
\hline & 1698 & Purén & 6 \\
\hline \multirow{6}{*}{$\begin{array}{l}\text { Hasta segundo tercio del XVIII: se } \\
\text { institucionaliza la práctica. Desafíos }\end{array}$} & 1716 & Tapihue & 5 \\
\hline & 1726 & Negrete $^{\star}(2)$ & 6 \\
\hline & 1738 & Tapihue $^{\star}(4)$ & 9 \\
\hline & 1746 & Tapihue $^{\star}(2)$ & 11 \\
\hline & 1759 & Concepción* (3) & 3 \\
\hline & 1760 & Santiago* (2) & 4 \\
\hline \multirow{6}{*}{$\begin{array}{l}\text { Último tercio del XVIII: auge del modelo. } \\
\text { Creación de una nueva inteligibilidad } \\
\text { mutua en los últimos parlamentos }\end{array}$} & 1771 & Negrete $^{\star}(3)$ & 22 \\
\hline & 1774 & Tapihue & 26 \\
\hline & $1783-1784$ & Lonquilmo* (7) & 53 \\
\hline & 1793 & Negrete $^{\star}(27)$ & 77 \\
\hline & 1803 & Negrete $^{*}(3)$ & 38 \\
\hline & Total & & 342 \\
\hline
\end{tabular}

* Parlamentos de los que tenemos más de una pieza documental o bien donde varias reuniones se registran en una misma pieza (se indica entre paréntesis el número de piezas). Las negritas de la última columna destacan las frecuencias más altas. 
Como se puede observar, en los primeros tratados firmados entre fines del XVI y principios del XVII (Quilacoya 1593; Concepción 1605; Paicavi 1612; Catiray 1612; Nacimiento 1617) la frecuencia de la palabra oscila entre 2 y 6 . Se incrementa notablemente entre 1692 y 1694 , alcanzando 22 ocurrencias en el parlamento de Concepción (1693), regresa casi a su frecuencia inicial en los dos primeros tercios del XVIII, para retomar un camino ascendiente a partir de 1771, alcanzando su frecuencia máxima en el parlamento de Negrete de 1793. Cabe mencionar que los expedientes de los parlamentos del XVIII suelen ser más voluminosos a medida que avanza el siglo, siendo el más nutrido el de Negrete (1793), que se compone de 27 piezas documentales ${ }^{16}$. ¿Cómo explicar los dos picos de frecuencia observados en nuestro corpus?

Las variaciones frecuenciales se deben tanto a factores contextuales o extralingüísticos, como cotextuales, es decir, intratextuales, distinción metodológica establecida hace décadas por varios investigadores, entre los cuales J.L. Catford (1965/1970), y que nos parece útil conservar.

\subsection{Algunos indicios contextuales}

Desde el punto de vista contextual, los picos frecuenciales, que hay que interpretar con cierta cautela en función del número de piezas documentales consideradas, corresponden a dos momentos históricos por supuesto distintos. Si bien los parlamentos se convocan generalmente después de fuertes sublevaciones indígenas y hostilidades entre mapuche y españoles, en los que hay ruptura de la paz acordada en el parlamento o tratado anterior, el parlamento de Yumbel, de 1692, que arroja 15 ocurrencias de la palabra parlamento, tiene lugar por primera vez fuera del territorio propiamente mapuche, en la zona fronteriza del río Biobío, preferencia que se mantendrá durante todo el XVIII (Zavala 2011: 150). Es el segundo Parlamento General explícitamente identificado como tal, y tiene lugar 45 años después del primero, el de Quillín (1647), lapso de tiempo considerable entre dos parlamentos generales que no se repetirá. Los parlamentos posteriores serán mucho menos espaciados.

Los de Negrete (1771) y Tapihue (1774), y en menor medida los de Lonquilmo (1783-84) y Negrete (1793 y 1803), se realizan después de varios años de sangrientas revueltas (Zavala 2011: 121), pero inauguran definitivamente una nueva etapa en las relaciones hispano-mapuches después de dos siglos de prácticas negociadoras. Acontecimientos de diversa índole inciden en el nuevo giro de las negociaciones: la expulsión de los jesuitas de todo el territorio hispanoamericano, las reformas borbónicas, las guerras que lleva la corona española en distintos frentes y los fuertes vientos revolucionarios que soplan tanto en América como en Europa. El mantenimiento del ejército español en Chile y los parlamentos en sí mismo representan un gasto considerable para la Corona (Zavala 2011), hecho consignado en los parlamentos de la segunda mitad del XVIII, y España requiere consolidar a sus amigos internos para poder luchar contra los enemigos externos (ingleses y holandeses, en particular, que acechan las costas del Pacífico). Por otro lado, en el terreno de la negociación propiamente dicha, entra en acción un personaje central, el gobernador de origen irlandés Ambrosio O'Higgins, que desempeñará un papel fundamental en las relaciones hispano-mapuche de fines del XVIII y principios del XIX (Zavala y Payàs 2015). 


\section{Trayecto temático-discursivo de la noción-concepto de parlamento}

\subsection{Los parlamentos del XVII y el control paulatino de una práctica ajena}

\subsubsection{Los inicios}

Hasta el Parlamento General de Quillín (1647), si exceptuamos las formulaciones del padre Luis de Valdivia anteriormente mencionadas en las que el referente de la palabra parece tambalearse, el parlamento atañe exclusivamente a una práctica política autóctona. En las 14 ocurrencias restantes del vocablo contabilizadas entre 1593 y 1641, encontramos 9 enunciados en los que la palabra está en posición objeto, en ocasión precedida del posesivo de tercera persona, generalmente adentro de la colocación hacer parlamento, y los sujetos gramaticales mencionados remiten las más de las veces a actores indígenas: «habiendo hecho sus parlamentos» (Paces de Quilacoya, 1593: 39), «y habiendo hablado sobre esto con grande concierto y elegancia Lincopichon y Antegueno (que son naturalmente retóricos estos indios, y se precian de hacer un buen parlamento)» (Paces de Quillín 1641: 130).

\subsubsection{Los indicios discursivos de la apropiación en la segunda mitad del XVII}

A partir del Parlamento General de Quillín (1647), en el que encontramos escasas 6 ocurrencias de la palabra, observamos un cambio notorio. Si bien el parlamento sigue siendo asunto autóctono «en el parlamento que hicieron para averiguar la dicha traición» (Parlamento de Quillín 1647: 194), empieza a aparecer la autoridad española como sujeto activo de la convocatoria: «Su Señoría, el Presidente Don Martín de Mújica. Gobernador y Capitán General de este reino, dijo que las cosas que se hubieren de tratar con los toques ${ }^{17}$ y caciques que han pedido la paz en la junta y parlamento general que tiene mandado hacer con ellos...» (Parlamento de Quillín 1647: 139), enunciado que se repetirá con algunas variantes en la mayoría de los parlamentos posteriores.

Varios son aquí los indicios lingüístico-discursivos que construyen y asientan una nueva relación hispano-mapuche en torno al parlamento. En primer lugar, y por primera vez, el vocablo parlamento está modificado por el adjetivo «general», que cualifica los grandes parlamentos con las cuatro parcialidades mapuche, o butalmapus. En segundo lugar, los toques y caciques piden la paz a una autoridad que «tiene mandado» hacer el parlamento. Los primeros piden, la autoridad otorga, dando a entender que empieza a moverse la interacción discursiva entre las dos comunidades. No son ellos los que «hacen parlamento» sino que «se hace parlamento con ellos». De ahora en adelante, son los españoles los que convocarán a parlamento y son los indios que pedirán paz, y veremos más adelante esta relación confirmada por el uso de los performativos correspondientes. En segundo lugar, la palabra parlamento está en coocurrencia con la palabra junta: «junta y parlamento», coocurrencia que observaremos muy a menudo, dando lugar incluso a una relación de correferencialidad. Si bien la relación de coordinación contenida en «junta y parlamento» sugiere todavía cierta ambigüedad -la coordinación puede implicar dos referentes distintos o una simple relación de aposición-, no son pocos los casos en los que junta sustituirá a parlamento, equivalencia que reducirá el vocablo a un solo sentido. El conteo lexicométrico de junta arroja 13 ocurrencias en Quillín (1647) contra 7 de parlamento, prueba de que la denominación parlamento para designar las negociaciones interétnicas no está todavía afianzada. 


\subsection{Los indicios de una práctica política institucionalizada de fines del XVII}

\subsubsection{Los discursos referidos y el control del léxico}

El siguiente Parlamento General (Yumbel 1692), celebrado cuarenta y cinco años después, parece confirmar el uso de parlamento en su sentido de junta, así como el papel rector de la autoridad española en dicho acto. En las 15 ocurrencias del vocablo, todos los caciques junto con los capitanes del ejército y las distintas autoridades «acuden al parlamento», «se juntan para hacer parlamento», bajo las órdenes del «Gobernador y Capitán General [...] por cuya orden se convocó dicho parlamento» (Parlamento de Yumbel 1692: 191), el «señor Presidente solicitaba hacerles partícipes de tanto que les declaraba, en este parlamento como en los demás» (Parlamento de Yumbel 1692: 204).

Las reiteradas menciones de las colocaciones "parlamento general», «dicho parlamento» en todas las intervenciones, españolas y mapuche, dan cuenta de la vitalidad tanto de una práctica, como de la palabra y su uso.

La mayoría de los discursos atribuidos a los caciques se refieren bajo la modalidad de un discurso indirecto y escenifican tanto las interacciones entre los caciques y las autoridades, como las de los caciques entre sí. En todos ellos abundan los ilocutivos (Austin 1970; Searle 1972, 1982; Escandell Vidal 1993; Kerbrat-Orecchioni 2001), de agradecimiento, reconocimiento y aceptación de lo pactado: «Siguió el cacique Curilpique [...] y en una larga narrativa dijo que admitía de buena voluntad todos los capítulos que les habían dado a entender» (Parlamento de Yumbel 1692: 203-204); «Y puesto de pie dicho cacique Loncotipai (...) pasó por el concurso de más de mil caciques de más alta clase, diciéndoles que no tenía que decir en todo lo tratado sino darles muchas gracias de que hubiesen aceptado unidos y conformes todo el parlamento...» (Parlamento de Yumbel 1692: 207).

Sin embargo, pese a la aceptación que muestran los mapuche en sus discursos, al volverse monosémica, es decir, al denominar casi exclusivamente la reunión interétnica convocada por el bando español, pues todo parece indicar que se abandonó la búsqueda de esa inteligibilidad mutua iniciada otrora por Valdivia (Payàs, Zavala et al. 2012: 3), la palabra y la práctica que designa pasan a integrar un léxico controlado por la corona. Cabe recordar aquí lo expresado por Simone Bonnafous y Maurice Tournier:

Aprendamos a considerar el discurso político y sus palabras como las armas que eran antes de volverse lenguaje, como armas diferidas. Así se entiende porque la acción política puede definirse como una lucha por la apropiación de los signos-poderes. (Bonnafous y Tournier 1995: 68) $)^{18}$

Si bien el contexto político en el que se inscriben nuestros textos es bien distinto al que se refieren Bonnafous y Tournier, las actas de los parlamentos siguen siendo documentos redactados desde y para el poder político de la corona española. Los dos parlamentos siguientes, Concepción (1693) y Choque Choque (1694), inmediatamente posteriores al de Yumbel, arrojan las frecuencias del vocablo más altas del siglo XVII y confirman la institucionalización de la práctica. Son cada vez más frecuentes las referencias a los parlamentos anteriores: el de Concepción hará referencia al parlamento de Yumbel (9 veces), y el de Choque Choque al de Concepción y al de Yumbel (8 veces), prueba de una memoria histórica, institucional y jurídica. Si bien observa- 
mos en el parlamento de Concepción todos los cotextos observados anteriormente: "se hizo dicho parlamento», "llamados para el parlamento general», «los que se hallaban en el parlamento», «se concluyó el parlamento», «en este parlamento como en los demás», emerge un nuevo sintagma, el de «capitulado/pactado en este parlamento» (Parlamento de Concepción 1693: 216) con lo que se formaliza la función del tratado: el parlamento entraña una serie de capitulaciones que los caciques prometen respetar, promesa cuyo incumplimiento será objeto de reproche y castigo. El papel rector de la autoridad se expresa generalmente al inicio del acta, y el intérprete es quien empieza el parlamento:

y el dicho intérprete general, por orden de su Señoría, principió el parlamento declarando a dichos caciques y dándoles a entender lo contenido en los capítulos siguientes... (Parlamento de Yumbel 1692, op.cit: 197)

\subsubsection{El discurso mapuche legitimado}

Sin embargo, junto con la formalización protocolar de la autoridad del rey y sus representantes en los parlamentos, los documentos muestran que se da cada vez más espacio a los discursos mapuche, referidos por supuesto en español, por lo tanto, traducidos, donde se precisa cuál de los caciques toma la palabra, lo que pide, lo que acepta, y en repetidas ocasiones, como ya lo mencionamos, sus muestras de agradecimiento y lealtad hacia el rey. Son discursos referidos «en cascada» en los que se construyen varias escenas de enunciación (Maingueneau 1998, 2014, 2015; Charandeau y Maingueneau 2002/2005), cuya dimensión argumentativa (Amossy 2000) es notoria ya que la mayoría de ellos construyen a sus enunciadores en el reconocimiento de las bondades prodigadas por los españoles. Sin embargo, al lado de discursos referidos como «...había reconocido él [el cacique Carilab] y todos los demás el gran bien y utilidad que se les había seguido vivir entre los españoles, muy estimados de todos y que habían recibido la ley de Cristo...» (Parlamento de Concepción 1693: 216), tenemos algunos otros como «Y que verdaderamente es tan gustoso porque habiendo comunicado ocho o diez gobernadores (...) a ninguno de ellos había oído en ningún parlamento mudar el estilo de hablar en usanza y ritos de ellos ...» (Parlamento de Yumbel 1692: 207), discurso en el que el cacique se muestra agradecido por el respeto que tiene el gobernador en turno, al contrario de los anteriores, hacia la «usanza y ritos de ellos». Aunque sabemos que el informe final pasa forzosamente por una selección de los discursos referidos, éstos son reveladores, tanto de prácticas intraétnicas a las que los españoles estaban muy atentos, como de las tensiones interétnicas y de las estrategias discursivas y argumentativas para sortearlas.

Veremos que estos dos aspectos fundamentales de los parlamentos: autoridad absoluta de la corona y capacidad negociadora de unos y otros, se profundizan a lo largo del siglo XVIII sin que por ello sean garantes del final de las hostilidades o de la paz, cuya fragilidad se percibe a lo largo de los once parlamentos celebrados durante el XVIII.

\subsection{Los parlamentos del XVIII}

\subsubsection{La práctica desafiada y la inteligibilidad cuestionada}

No deja de extrañarnos que la frecuencia de la palabra parlamento vuelva a bajar considerablemente hasta el último tercio del siglo XVIII, es decir hasta el parlamento 
general de Negrete en 1771. En los documentos correspondientes, los cotextos inmediatos de la palabra parlamento no arrojan mucha novedad, salvo la ocurrencia de una nueva colocación: "celebrar parlamento»: «se celebró el parlamento en la mejor forma que se puede con gente rústica y bárbara» (Parlamento de Tapihue 1716: 254), que se impondrá paulatinamente a partir de 1746.

El parlamento ya está consagrado como práctica ritualizada de las relaciones hispano-mapuches, como lo indica el gobernador Amat y Junyent en carta al rey Fernando VI: «En el parlamento general que, siguiendo el rito de este gobierno hice a los indios a mi ingreso a servirlo» (Parlamento de Concepción, 1759: 321). Se hace referencia sistemática a los parlamentos anteriores: «que como leales vasallos de su Majestad (que Dios guarde), observarán, guardarán y cumplirán todo lo que tienen prometido y jurado en todos los antecedentes parlamentos» (Parlamento de Tapihue 1746: 316), pero la relativa frecuencia con la que se realizaron permite inferir unas relaciones sumamente difíciles entre los dos bandos. Los informes dan cuenta de ello sin reparo alguno: «Se pasó a hacer parlamento en el paraje de Tapihue, el cual no tuvo el logro de serenar los ánimos» (Junta de Guerra previa al Parlamento general de Negrete 1726: 274); algunos de los gobernadores se quejan de la falta de compromiso de los indios, mencionan en reiteradas ocasiones su no asistencia a las negociaciones, y ante el fracaso de los parlamentos buscan construir ante el rey una imagen de sí mismos, un ethos dicho (Maingueneau 2014) de esforzados y hábiles negociadores: «Yo, aunque procuré acariciar a unos y otros lo mejor que pude con las palabras y con el obsequio, y esforzando la persuasión...» (Carta del gobernador Manuel de Amat y Junyent en Concepción 1759, op.cit: 322), donde se ponen de manifiesto las tensiones entre las dos comunidades. El tono de las capitulaciones es cada vez más autoritario, y los caciques mapuches están construidos en la súplica, pidiendo perdón, reconociendo sus errores, «manifestando su rendimiento» (Parlamento de Concepción 1759: 324). Aunque los informes contienen por lo general el listado de caciques y participantes (a veces más de doscientos nombres), y es sabido que, según los protocolos indígenas, todos los principales debían hacer uso de la palabra, en este periodo son pocos los discursos referidos atribuidos a caciques que tienen nombre y apellido, y cuando los hay, están negativamente evaluados:

Y puestos en pie, y siendo preguntados por medio del intérprete qué era el asunto de su venida hasta esta ciudad, tomaron la palabra los caciques don Pablo Liguenpichum y don Gabriel Ancalevi y, después de muchos preámbulos y alegorías que usan al estilo oriental, dijeron... (Parlamento de Santiago 1760: 332)

Aunque muchos de los parlamentos anteriores solían hacer hincapié en los extensos turnos de habla de los participantes mapuche, el presente comentario apunta hacia una descalificación del habla autóctona, cuya extrañeza y lejanía se subraya: «muchos preámbulos y alegorías que usan al estilo oriental...», comentario radicalmente opuesto a lo expresado por el relato jesuita del parlamento de Quillín siglo y medio antes: «son naturalmente retóricos estos indios» (Paces de Quilín 1641: 130). El comentario de Valdivia evocaba una suerte de retórica universal, o sea, propia de la razón occidental, mientras que «al estilo oriental», expresión que encontramos en otros documentos de la época, remite a una otredad ajena, e inferior, debe entenderse, a la civilización occidental ${ }^{19}$. La descalificación de los actores mapuche está confirmada por el modo en que los introducen en el escenario enunciativo, "y siendo 
preguntados por medio del intérprete», giro pasivo con el que se les despoja incluso de la responsabilidad del acto de habla en favor del intérprete y lengua general «llamado primero y ante todas cosas» para iniciar el parlamento (Parlamento de Santiago 1760: 331).

\subsubsection{El auge y el restablecimiento de la inteligibilidad}

Al parecer, la situación cambia radicalmente en los últimos cuatro parlamentos del siglo XVIII, en los que observamos una curva nuevamente ascendiente de la frecuencia del vocablo. El contexto político en el que se inscriben y del que hemos hablado anteriormente desempeñó indudablemente un papel fundamental. Paralelamente, los expedientes con los que contamos son más nutridos que los anteriores, lo cual contribuye en parte al aumento de la frecuencia. Pero independientemente de estos dos factores, que remiten más bien a una exterioridad discursiva, el rastreo sistemático de los cotextos de parlamento, como se verá a continuación, permite detectar varios cambios tanto en el escenario construido como en el haz temático en el que el vocablo toma cuerpo. Si bien están presentes todas las colocaciones ya mencionadas, como «acuden al parlamento», «se convoca a parlamento», «se mandó hacer parlamento», «se dio principio al parlamento», etc., en las que abundan por supuesto las referencias a los anteriores/posteriores parlamentos, así como a «este/dicho parlamento», donde el deíctico alterna con el anafórico, algunas se hacen más sistemáticas, como se verá a continuación.

\section{El universo discursivo de la institucionalización de una práctica}

A partir de Negrete 1771 los parlamentos ya no se convocan (en el sentido de un mero llamado a asistir), sino que sistemáticamente se celebran ${ }^{20}$, aunque los actores mapuche sigan construidos en la demanda, es decir, en posición de inferioridad: «varias prudentes reflexiones, con acuerdo de repetidas juntas de guerra, movieron mi dictamen a que [....] sin intermisión alguna se celebrase el parlamento que pedían» (Acta de Junta de guerra ${ }^{21}$. Parlamento de Negrete 1771: 347). Lo anterior no significa que hayan desaparecido por completo las fórmulas de autoridad como «Este parlamento manda Su Majestad que se haga...» (Parlamento de Lonquilmo 1783-84: 461), donde está presente la fórmula más clásica de «hacer parlamento»; sin embargo, son muy escasas. En el parlamento de Negrete (1793), por ejemplo, encontramos 14 ocurrencias de «celebrar/celebración/celebrado» el parlamento, mientras que una sola ocurrencia de «hacer parlamento». En la mayoría de las cartas de O'Higgins que se incluyen, sea al Gobernador de Concepción, al Virrey o al Rey, en las que O'Higgins habla en primera persona del singular: «En el parlamento que tenía premeditado celebrar», «Hallándome resuelto a celebrar dentro del verano inmediato el parlamento general con los indios...» (Parlamento de Negrete 1793: 486), el parlamento «se celebra». Aunque no debemos sobreinterpretar la nueva colocación, fruto de los usos y costumbres del lenguaje administrativo de la España borbónica, no podemos ignorar tampoco que la palabra celebrar, así como sus derivados, no entraña connotación autoritaria, sino más bien la de acontecimiento y festejo para todos los participantes que concurren al acto. Es más, no son pocas las expresiones de gusto presentes en los informes después de la celebración de algún parlamento, como lo expresa O’Higgins al Gobernador Ambrosio Benavides: «He dado cuenta a Vuestra Señoría de haberse 
logrado celebrar con toda la felicidad que puede desearse el parlamento general con los indios de estos países...» (Parlamento de Lonquilmo 1783-84: 472).

Esta presencia marcada de la designación "parlamento» en el léxico de las autoridades españolas en Chile se acompaña de la desaparición de algunos vocablos con los que estaba en relación de correferencia, y aparecen otros, que permiten completar el trayecto temático de la noción-concepto de parlamento.

\subsection{Algunas alternancias significativas}

\subsection{1. «unta» versus «congreso»}

Según el rastreo lexicográfico, la palabra junta, que en los parlamentos del siglo XVII mostraba una frecuencia bastante elevada, desaparece prácticamente de los parlamentos del XVIII. Fuera de las Juntas de guerra que corresponden a las reuniones españolas previas a los parlamentos, junta muestra una frecuencia que oscila entre 1 y 3 en los parlamentos del siglo XVIII, generalmente para designar reuniones de los mapuche, y los cotextos en los que se inserta están evaluados en forma negativa, como en el ejemplo siguiente: «Que en consecuencia [...] los indios [...] deben deponer las armas, disolver las juntas, convocatorias o cualesquiera otros pactos que, según sus ritos y costumbres hayan celebrado para el alzamiento...» (Parlamento de Negrete 1771: 348). La asociación del vocablo junta, arrastrando de paso sus aposiciones coocurrentes «convocatorias o cualquier otro pacto», con el de alzamiento sugiere que la palabra junta, otrora en correferencia con parlamento, abandona el terreno de la negociación hispano-mapuche para designar exclusivamente los pactos autóctonos, designación que se conservará a lo largo del siglo XIX (Payàs, Zavala et al. 2015). A prueba de ello, en el mismo parlamento, tenemos 4 ocurrencias de congreso, en posición de correferencia con parlamento, como en el enunciado siguiente:

La firmó el señor presidente y el ilustrísimo señor obispo de la Concepción, el auditor general de guerra, el señor maestre de campo general y los otros señores y reverendos padres concurrentes a dicho general congreso, de lo que doy fe. (Parlamento general de Negrete 1771: 438)

La correferencia congreso/parlamento seguirá aumentando en los siguientes parlamentos y la palabra congreso alcanzará una frecuencia de 17 ocurrencias en el último parlamento de Negrete (1803).

\subsection{2. «Parlamento» versus «parla»}

En un trabajo anterior citado al inicio de estas páginas (Payàs, Curivil et al. 2012) en el que analizamos los derivados neológicos parlar y parla que aparecen con cierta frecuencia en los parlamentos de fines del XVIII, sugerimos que tanto el verbo parlar como el sustantivo parla, que fueron designando las actividades discursivas de los mapuche, podrían ser traducciones y/o equivalentes de los derivados existentes en mapudungun, como lo confirma el diccionario del jesuita Andrés Febrés (1765: 457)

Después de la presente investigación, podríamos quizá completar nuestro análisis con la siguiente observación. Si bien parla se utiliza exclusivamente para designar las negociaciones o el habla mapuche, y siempre se refiere al discurso de un enunciador mapuche, su contexto de aparición corresponde al momento de apropiación por parte de las autoridades españolas de la palabra parlamento. 
El primer registro de parla, en plural o en singular, aparece en el parlamento de Tapihue (1738) donde arroja 4 ocurrencias, reaparece en Lonquilmo (1783-84) con 5 ocurrencias, para alcanzar una frecuencia de 8 en Tapihue (1774) y de 5 en Negrete (1803).

Los cotextos registrados, en la mayoría de los casos, escenifican a los mapuches hablando entre ellos, como se puede ver en los siguientes ejemplos: «con lo que concluyeron sus parlas y mutuos consejos aceptando lo mismo que pidieron en lo tocante a los padres misioneros...» (Parlamento de Tapihue 1738: 356); «y pedida la licencia acostumbrada, que se le concedió, dio principio a la parla con todos los caciques y demás butalmapus» (Parlamento de Tapihue 1774, op.cit: 402), "Antes de empezar la parla se presenta Lebuepillan» (Parlamento de Negrete 1793: 511), «don Ignacio Naipaylican, conforme a la preferencia antigua que tiene en estos casos, y concedida, dirigió su parla a todos los caciques presentes» (Parlamento de Negrete 1803: 543).

Como lo podemos observar, el vocablo parla tiende a aparecer en cotextos muy similares a aquellos de la primera mitad del siglo XVII, en los que se usaba la palabra parlamento para designar una práctica autóctona (su/sus parlamentos), así como lo apuntamos a principio de este análisis.

Si bien detectamos algunas ambigüedades en las que la palabra parece designar el habla de ambos bandos o la negociación misma, como en los ejemplos siguientes: «comparecieron con prontitud caciques e indios en la ramada dispuesta para la parla» (Parlamento de Lonquilmo 1783-84: 402), o «se dirigió Su Señoría al paraje de la parla donde esperaban los caciques y don Agustín Curiñancu...» (Parlamento de Lonquilmo 1983-84: 462), ambigüedades que también habíamos observado en los primeros usos de parlamento, la tendencia parece irreversible, por un tiempo al menos. De ahora en adelante, la parla será asunto «de ellos». En el Diario del Parlamento de Negrete (1792-93), documento sin firma, pero atribuido a Judas Tadeo Reyes, secretario de O’Higgins, se lee: «habíamos descansado de indios y sus parlas» (Chauca 2006: 223), sintagma en el que la coordinación entre «indios» $\mathrm{y}$ «sus parlas», ambos objetos de la misma descalificación, no puede ser más explícita.

Una vez desplazada la noción-concepto parlamento del ámbito mapuche hacia el ámbito y dominio exclusivo de las autoridades españolas, fue necesario encontrar otra palabra para referirse a las prácticas discursivas intraétnicas de los mapuche en el contexto interétnico de los parlamentos hispano-mapuche. No podemos afirmar aquí que se haya tratado de una estrategia consciente de las autoridades, bajo la pluma de los redactores del informe. Sin embargo, por más ínfimo que sea el indicio, es revelador de cierta resistencia, por parte del bando español, a homologar, como lo había hecho Valdivia, las prácticas discursivas de los mapuche con las de los españoles.

\subsection{Recuperación de la voz autóctona y de la mutua inteligibilidad}

Paralelamente a la introducción de la designación parla reaparecen, en los últimos parlamentos del periodo, los discursos referidos atribuidos a los actores mapuche, bajo la modalidad de un discurso directo. En el documento del parlamento de Lonquilmo, por ejemplo, se introducen cuatro largos discursos directos de caciques mapuche, a los que cabe agregar múltiples inserciones de discurso indirecto que construyen a los actores mapuche en interacción: 
...[a] esto que separadamente proponía a los caciques, contestaban ellos en la misma forma, diciendo que conocían que era cierto y de razón cuanto se les aconsejaba y que ya advertían que era todo efecto del amor y compasión que se les tenía... (Parlamento de Lonquilmo 1783-84: 549)

En el siguiente parlamento (Negrete 1793), después de las capitulaciones, se introducen nueve locutores mapuche, explícitamente nombrados con sus respectivos discursos: «Habla el cacique don Juan de Lebuepillan», «Habla el cacique don Lorenzo Catrilab», etc., enumeración que finaliza con el enunciado:

Y habiendo dicho en sustancia lo mismo noventa y ocho caciques más que hablaron sucesivamente hasta las tres de la tarde de este día, consintiendo todos gustosamente en la paz, y prometiendo unánimemente fidelidad al rey, unión, y conformidad con los españoles, se mandó suspender por ahora la parla. (Parlamento de Negrete 1793: 514)

Aunque sabemos que el discurso referido es construcción de quien asume la responsabilidad del acto de referir, razón por la cual siempre tiene una función argumentativa, tanto mediante la construcción del locutor referido como mediante el objeto discursivo referido (Ducrot 1984), y aunque la mayoría de los discursos referidos de los actores mapuche en los parlamentos los siguen escenificándolos como agradecidos al rey, la traducción de estos discursos da muestra no sólo del espacio de habla que se les da, sino de sus capacidades argumentativas para convencer a los otros caciques de la legitimación de la paz que el rey les ofrece. La profusión de discursos referidos, generalmente desprovistos de un metadiscurso connotado negativamente, sugiere asimismo la construcción de un destinatario mapuche, cada vez más bilingüe. Al respecto, llama la atención el siguiente comentario del escribano al referir el discurso de la autoridad española: «...razonó Su Señoría en alta voz comprensible a todo el auditorio en esta forma...» (Parlamento de Lonquilmo 1783-84: 464), enunciado del que se infiere que los representantes mapuche entienden en español el discurso del gobernador.

Asimismo, la carta que mandara por primera vez el gobernador Ambrosio O’Higgins al cacique de la Imperial, Don Felipe Inalicán, que figura entre los documentos del parlamento general de Negrete de 1793, en la que empieza dirigiéndose al destinatario como "Cacique Inalicán, y mi amigo» (Parlamento de Lonquilmo 1783-84: 490), construye a un destinatario mapuche con el debido respeto que debían mostrarle las autoridades españolas para el buen desarrollo de las negociaciones. En otras palabras, los discursos referidos de unos y otros construyen a nuevos actores involucrados de manera muy distinta en los parlamentos. Si bien la autoridad del parlamento sigue perteneciendo a la corona, la descripción cuidadosa del espacio físico de las negociaciones, la adopción de la ramada como marco de interacción, escenario totalmente mapuche, hace de estos parlamentos un espacio de intercambio más equitativo.

\section{Conclusión}

Partiendo de investigaciones anteriores, en las que destacamos el papel de los intérpretes en la construcción de un léxico político que fijó las relaciones hispano-mapuche a lo largo de dos siglos, intentamos aquí seguir el recorrido de la noción-concepto de parlamento y su red temática, para aprehender mejor los movimientos de dicho 
léxico. No es frecuente que la historia de la traducción incursione en el terreno más incierto de lo que las palabras han podido significar a lo largo del tiempo. Suele ser tarea de otras disciplinas, como la historiografía lingüística; y sin embargo, la mirada traductológica, acompañada de una minuciosa descripción de las estrategias discursivas utilizadas por los actores de la interacción, permite ver cómo es la vida de las palabras y los conceptos que vehiculan, en contextos bilingües como el que nos ha interesado aquí. Por medio de la traducción se hicieron inteligibles conceptos fundamentales de las sociedades en contacto, ciertamente, pero las equivalencias así creadas no fueron unívocas ni permanecieron inalteradas, pues estaban vinculadas a dinámicas interétnicas y relaciones de poder. Por eso el estudio de la traducción no puede detenerse en el acto primero de traducción. El genial hallazgo de Luis de Valdivia que hizo equivalentes las tradiciones de diplomacia indígena y europea puede ser objeto traductológico, pero su estudio no se agota ahí.

¿Hasta dónde podemos extender la mirada traductológica? ¿Cómo medir el lugar de la traducción, el de sus actores, sus estrategias, cuando no se tienen textos fuentes, porque nunca existieron o porque se han perdido, o cómo dar cuenta de una investigación que pudiera interesar conjuntamente a los traductores, los historiadores, los lingüistas? ¿Cómo definir esta mirada traductológica cuando difícilmente podemos acotar las condiciones de producción de lo traducido, cuando estamos frente a documentos polifónicos, caracterizados por múltiples heterogeneidades enunciativas, múltiples reescrituras, y sin embargo, en los que la traducción no se puede ignorar?

Considerar la traducción como constitutiva de los discursos que analizamos implica abordarlos desde un enfoque traductológico muy amplio. Extender la mirada traductológica hasta los efectos, a lo largo de un siglo y medio, del gesto inaugural de Valdivia es lo que aquí hemos intentado. En este recorrido, en el que adoptamos una metodología discursiva, tanto por opción disciplinar como por las limitaciones a que estamos sometidos en historia de la traducción cuando no se pueden realizar cotejos entre fuente y meta, se revelan, gracias a la perspectiva traductológica, las intencionalidades de los agentes que problematizaron, consciente o inconscientemente, desde sus inicios, la equivalencia coyagtun=parlamento. Esta equivalencia, forjada en un instante de oportunidad ético-política, donde pareció posible y conveniente celebrar pactos entre dos naciones beligerantes, tuvo que ser puesta a prueba constantemente, al azar no sólo de las vicisitudes lingüísticas que se fueron dando (las lenguas también tienen vida propia), sino también de los cambios de clima político.

Trabajar desde la microescala de la palabra traducida, desplazada, sustituida, a través de los discursos de los actores donde tomó cuerpo, nos permitió encontrar indicios de cómo operan las tensiones y conflictos de las relaciones coloniales, pero también sus acomodos y negociaciones. Y es en la larga duración de la historia de su uso donde se pueden hacer visibles.

\section{NOTAS}

1. Este trabajo se ha realizado en el marco del proyecto CONICYT-PAI -MEC 80150084: Fortalecimiento de los estudios de traducción y discurso político (mapudungun-castellano y otras lenguas) en investigación y en docencia de pregrado y postgrado de la Universidad Católica de Temuco, Chile, así como del Proyecto VIPUCT 2016GI-JZ-03. Las autoras agradecen a José Manuel Zavala las observaciones hechas al manuscrito.

2. El Ejército de la Frontera fue el único ejército permanente que tuvo España en sus posesiones americanas. Tuvo una planta estable y remunerada ya a partir de 1603, tras el repliegue español al 
norte del río Biobío, obligado por un gran alzamiento indígena (1598-1600) que destruyó las ciudades y enclaves hispanos situados al sur de la ciudad de Concepción.

3. Ius Gentium, Derecho de gentes. Antecedente del actual derecho internacional.

4. No se conocen escritos en mapudungun durante el periodo colonial fuera de los escritos misionales.

5. Lengua (masculino, en general) es sinónimo de intérprete, especialmente en las crónicas de Indias. El cargo de lengua general o intérprete general está documentado en Chile desde inicios del periodo colonial.

6. De ahora en adelante, todos los fragmentos citados de los parlamentos se extraen del mismo volumen editado por Payas 2018, razón por la cual sólo indicaremos el nombre del parlamento, su fecha y la página correspondiente a la cita.

7. Los parlamentos hispano-mapuches son un caso singular por su antigüedad, continuidad y resultados políticos, pero la diplomacia entre potencias coloniales y pueblos indígenas no fue una práctica aislada (ver, en particular, Levaggi 2002).

8. Llamamos documento a la unidad de texto de archivo, que a veces puede contener más de una sola pieza documental, en general el acta o registro oficial del parlamento. Cada documento corresponde, por lo tanto, a un parlamento.

9. En esta descripción factual de cómo fue comprendida la práctica mapuche seguimos en lo sustantivo lo expuesto en Payàs, Zavala et al., 2015.

10. Así se nombran los que se consideran antecesores, en 1593, 1605 y 1612. También se conocieron como «paces» las de Quillín, de 1641.

11. Los españoles propagaron la palabra antillana cacique, que vino a reemplazar en el resto de los territorios conquistados a las denominaciones que en cada lengua se daba a las autoridades propias. En Chile, reemplazó a veces el nombre de los jefes militares (toki, o toque, españolizado en las actas) y autoridades civiles (ülmen).

12. «Memoria como se han de entender las provisiones de los indios de Chile y algunos tratos particulares que entre ellos tienen». El documento en sí es apócrifo, pero en la versión actualizada del mismo (Payàs, 2018: 45) se confirma la atribución al P. Luis de Valdivia.

13. Instituto de Investigación Rafael Lapesa (2013): Corpus del Nuevo diccionario histórico. Madrid: Real Academia Española. Consultado el 3 de octubre de 2019, <http://web.frl.es/CNDHE $>$.

14. La palabra francesa parlement designa desde el siglo XIII una curia regis en session judiciaire, sentido que conservará hasta 1790, contrariamente al inglés que adquiere rápidamente el sentido de asamblea legislativa. (Le Robert, Dictionnaire historique de la langue française, 1998, p. 2578).

15. El proyecto pacificador conocido como Guerra Defensiva, del que Valdivia es principal promotor, será finalmente desacreditado y abandonado. Valdivia regresará a España, y morirá en Valladolid en 1642. Sin embargo, la diplomacia hispano-mapuche que él instauró se mantendrá durante más de dos siglos.

16. Asimismo, consideramos para el cotejo general la descripción del Ceremonial que José Manuel Zavala incluyó en su edición de 2015, ya que constituye una descripción minuciosa de los hechos narrados, ya sean «hechos del hacer» $\mathrm{o}$ «hechos del decir», distinción establecida por Charaudeau (1997/2003) para el discurso de prensa, y que resulta de gran utilidad en nuestros informes parlamentarios, constituidos, como ya se señaló, no sólo por descripciones de los hechos físicos, sino también por múltiples discursos referidos.

17. Aquí parece distinguirse a los jefes militares (toques), de los caciques, estos como autoridades políticas.

18. La traducción es nuestra.

19. Encontramos una expresión muy parecida en el Diario del Parlamento de Negrete (1792-93), al justificar así la inclusión en el diario de una carta mandada por O’Higgins a varios caciques: «pues no dejará de agradar por la singularidad del estilo oriental en que fue concebida» (Chauca 2006: 221). El adjetivo «oriental» en lengua castellana data de 1438 (Corominas 1987: 426), y todo indica que en nuestros ejemplos describe como en francés una otredad casi genérica, frecuentemente asociada a lenguas de tradición oral como «lenguas orientales». Por el francés, véase REy, Alain (1998): Dictionnaire historique de la langue française. Vol. 2. F-PR. París: Dictionnaires Le Robert, 2487.

20. Cabe recordar que la colocación surge una primera vez en el parlamento de Tapihue, en 1746, pero tarda medio siglo en generalizarse.

21. Uno de los 15 firmantes es Ambrosio O’Higgins, aunque todavía no como gobernador. 


\section{REFERENCIAS BIBLIOGRÁFICAS}

Amossy, Ruth (2000): L'argumentation dans la langue. París: Nathan Université.

Austin, John Langshaw, (1970): Quand dire c'est faire. París: Seuil.

Authier-Revuz, Jacqueline (1984): Hétérogénéité(s) énonciative(s). Langages. 73:98-111.

BENGOA, José (2007): El tratado de Quilín: documentos adicionales a la historia de los antiguos Mapuches del sur. Santiago: Catalonia.

Blum-Kulka, Soshanna (2000): Pragmática del discurso. In: Teun Van Dijk, ed. El discurso como interacción social. Barcelona: Gedisa, 67-99.

Bonnafous, Simone y Tournier, Maurice (1995): Analyse du discours, lexicométrie, communication et politique. Langages. 117:67-81.

CATFORD, John (1965/1970): Una teoría lingüística de la traducción. Ensayo de lingüística aplicada. (Traducido del inglés por Francisco Rivera Libro) Caracas: Editorial Universidad Central de Venezuela.

Corominas, Joan (1987): Breve diccionario etimológico de la lengua española. Madrid: Gredos.

Charaudeau, Patrick (1993): Grammaire du sens et de l'expression. Paris: Larousse.

Charaudeau, Patrick (1997/2003): El discurso de información mediática. (Traducido del francés por Margarita MizrajI) Barcelona/Buenos Aires: Gedisa.

Charaudeau, Patrick y Maingueneau, Dominique (2002/2005): Diccionario de Análisis del Discurso. (Traducido del francés por Irene Agoff) Buenos Aires/Madrid: Amorrortu.

Chauca, Jorge (2006): La frontera araucana. Diario del Parlamento de Negrete (1792-1793). Brocar. Cuadernos de Investigación Histórica. 30:207-240.

De Góngora Marmolejo, Alonso (1862): Historia de Chile desde su descubrimiento hasta el año de 1575. Santiago: Impr. del Ferrocarril.

De Vivar, Gerónimo (1558/1966): Crónica y Relación Copiosa y Verdadera de los Reinos de Chile. Santiago: Fondo Histórico y Bibliográfico José T. Medina.

Dillehay, Tom y Zavala, José Manuel (2013): Compromised Landscapes: The Proto-Panoptic of Colonial Araucanian and Spanish Parlamentos. Colonial Latin American Review. 22(3):320-342.

Ducrot, Oswald (1984): Le Dire et le dit. París: Minuit.

Ercilla, Alonso de (1569/1962): La Araucana. México, D.F.: Universidad Nacional Autónoma de México.

EsCandell, M. Victoria (1993): Introducción a la pragmática. Barcelona: Antropos.

Febrés, Andrés (1765): Arte de la lengua general del Reyno de Chile. Lima: Calle de la Encarnación.

Guilhaumou, Jacques (2000): De l'histoire des concepts à l'histoire linguistique des usages conceptuels. Genèses. 38:105-118.

Guilhaumou, Jacques (2005): La langue politique et la révolution française. Langage et société. 3(113):63-92.

JаковSON, Roman (1959/1975): En torno a los aspectos lingüísticos de la traducción. In: Roman Jаковson. Ensayos de lingüística general. (Traducido del inglés por Josep M. PUjol y Jem CABANEs) Barcelona: Seix Barral, 67-77.

Kerbrat-Orrechioni, Catherine (2001): Les actes de langage dans le discours. París: Nathan.

Levaggi, Abelardo (2002): Diplomacia hispano-indígena en las fronteras de América. Historia de los tratados entre la monarquía española y las comunidades aborígenes. Madrid: Centro de Estudios Políticos y Constitucionales.

Maingueneau, Dominique (1998): Analyser les textes de communication. París: Dunod.

Maingueneau, Dominique (2014): Retour critique sur l'éthos. Langage et société. 149:31-48.

Maingueneau, Dominique (2015): Argumentation et scénographie. In: Carmen PineiraTresmontant, ed. Discours et effets de sens. Argumenter, manipuler, traduire. Arras: Artois Presses Université, 71-87.

Malvestitti, Marisa (2012): Mediación lingüística al Este de los Andes en la época del Awkan (fines del siglo XIX). In: Gertrudis PayÀs y José Manuel Zavala, ed. La mediación lingüísticocultural en tiempos de guerra. Temuco: Ediciones UC de Temuco. 
PAYÀs, Gertrudis (2018): Los parlamentos hispano-mapuches. Textos fundamentales. Versión para la lectura actual. Santiago/Temuco: Ed. Universidad Católica de Temuco/DIBAM/Centro de Investigaciones Diego Barros Arana.

PAyÀs, Gertrudis, Curivil, Ramón y Quidel, José (2012): Birreferencialidad en la traducción de términos clave de las negociaciones hispano-mapuches. Algunos ejemplos extraídos de las actas de los parlamentos del periodo de Ambrosio O'Higgins (1770-1803). Mutatis Mutandis. 5(2):249-258.

Payàs, Gertrudis., Zavala, José Manuel y Samaniego, Mario (2012): Al filo del malentendido y la incomprensión: el padre Luis de Valdivia y la mediación lingüística. Historia. 1(45):6990.

PayÀs, Gertrudis., Zavala, José Manuel y Paillavil, Ramón Curivil (2015): La palabra 'parlamento' y su equivalente en mapudungun en los ámbitos colonial y republicano. Un estudio sobre fuentes chilenas bilingües y de traducción. Historia. 47(2):355-373.

SeARLE, John R. (1972): Les actes de langage. París: Hermann.

SeARLE, John R. (1982): Sens et expression. París: Minuit.

Volóshinov, Valentín (1929/2009): El Marxismo y la filosofía del lenguaje. (Traducido del ruso por Tatiana Bubnova) Buenos Aires: Ed. Godot Argentina.

Zaslavsky, Danielle (2012): ¿Es la paráfrasis una estrategia de traducción? Discurso; teoría y análisis. 32:89-103.

Zavala, José Manuel y Payas, Gertrudis (2015): Ambrosio O'Higgins y los parlamentos hispanomapuches, 1771-1803: Política indígena, escritura administrativa y mediación lingüísticocultural en la época borbónica chilena. Memoria Americana. 23(2):103-136.

Zavala, José Manuel (2008): Los mapuches del siglo XVIII. Dinámica interétnica y estrategias de resistencia. (Traducido del francés por José Manuel Zavala y Carmen G. Garbarini) Santiago: Ed. Universidad Bolivariana.

Zavala, José Manuel (2011): Origen y particularidades de los parlamentos hispano-mapuches coloniales: Entre la tradición europea de tratados y las formas de negociación indígenas. In: David González, ed. Pueblos indígenas y extranjeros en la monarquía hispánica: La imagen del otro en tiempos de guerra (siglos XVI-XIX). Madrid: Sílex, 303-316.

Zavala, José Manuel (2015): Los parlamentos hispano-mapuches (1593-1803). Textos Fundamentales. Temuco: Eds. Universidad Católica de Temuco. 